\title{
Viability Evaluation of Domestic Solar Hot Water Systems using two Multi Criteria Evaluation Techniques: Case Study of an Urban Area in India
}

\author{
Morapakala Srinivas
}

\author{
Mechanical Engineering Department, BITS, Pilani-Hyderabad, Jawahar Nagar, Shameerpet Mandal, \\ Hyderabad 500078, India
}

\begin{abstract}
Despite the proven favourable techno-economic feasibilities along with the organised promotional measures, solar hot water systems are not diffused to the extent they should be, even in the domestic front of urban India where the potential for such dissemination is high. The reasons for such a low dissemination of domestic solar hot water systems (DSHWS) could be due to multi-criteria covering various dimensions of viability of domestic water heating options. This paper presents the work taken up to study the viability of DSHWS vis-à-vis other competing water heating options, on multi-criteria covering technical, economic, commercial, social and behavioural dimension in the urban India context, with a special reference to Bangalore. The strengths and weaknesses, significant dimensions and criteria for better dissemination of DSHWS vis-à-vis other competing water heating options, as obtained from the analysis using two multi criteria evaluation techniques viz. PROMETHEE and AHP are presented.
\end{abstract}

Keywords: Domestic solar hot water systems, multi criteria evaluation, viability, PROMETHEE, AHP.

\section{INTRODUCTION}

Owing to the several technological developments that happened over the decades, it is now established that, use flat plate collector (FPC) based thermosyphon domestic solar hot water systems (DSHWS) with electrical backup is one of the promising options for domestic water heating in India. Despite the proven favorable techno-economic feasibilities along with the organized promotional measures, such as capital subsidies in 1980s and 1990s; soft loans currently being given to meet up to $85 \%$ of the capital at an interest rate of $2 \%-5 \%$; rebates on electricity tariff and property taxes currently being offered for DSHWS users etc., for the last 25 years, DSHWS are not diffused in India to the extent they should be. The solar water heating potential in the country is around 140 million square meters of collector area where as the cumulative achievement by January 2012 is 4.98 million square meters of collector area [1].

In simplest terms, the main reason for low dissemination of DSHWS could be viewed as the perceived notion among the end users that "DSHWS are not viable compared to the other available alternative domestic water heating options". This very notion necessitates the definition and evaluation of the viability of water heating options so as to understand the factors affecting the dissemination of DSHWS.

*Address correspondence to this author at the Mechanical Engineering Department, BITS, Pilani-Hyderabad, Jawahar Nagar, ShameerpetMandal, Hyderabad 500078, India; Tel: +91-40-66303511; Fax: +91-40-66303998; E-mails: morasrini@gmail.com, morasrini@hyderabad.bits-pilani.ac.in
One water heating option is more viable compared to the other when that option is capable of serving its intended purpose of supplying hot water while satisfying a wide variety of criteria belonging to various "dimensions of viability". The "dimension of viability" can be seen as a group of several criteria of same category which have a direct or indirect bearing on the viability. The criteria that make the dimensions have a direct relevance with the "dissemination barriers" that impede the broader adoption of any water heating option. According to the studies related to dissemination barriers specifically on DSHWS [2-7] and also on other renewable energy technologies (RET) [813], the criteria can be grouped in to technical, economic, commercial dissemination, social and behavioural categories. These categories can be viewed as dimensions of viability with nature and number of criteria in each of the dimension depending on the problem domain in hand. All these suggest that viability evaluation of DSHWS is a multi-criteria evaluation (MCE) of performance of DSHWS vis-à-vis competing options with interdependent, interacting goals defined by the criteria of four dimensions of the viability.

It is well known that the perceptions of the end users and other stakeholders on particular technology play a vital role in the dissemination of any RET in general and DSHWS in particular. Specific to DSHWS in India, although there have been a limited number of reported works that involved the stakeholders' opinions in studying the barriers for the dissemination of DSHWS [2, 3, 7], there have been no attempts on 
multi-criteria evaluation of viability of DSHWS vis-à-vis other options taking the perceptions of stakeholders in to consideration.

Under this background, the present work was taken up to identify the relative strengths and weaknesses of various domestic water heating options with the input data derived from the stakeholders' perceptions on the performances of these options with respect to multicriteria belonging to different dimensions of viability and to evaluate the viability of DSHWS vis-à-vis other promising domestic water heating options using MCE techniques.

The methodology adopted is similar to any classical MCE procedure which can broadly be divided in to three phases viz. data preparation, selection and application of an MCE aggregation method and interpretation of the results. Following sections present the details of various phases undertaken for the present viability evaluation studies.

\section{DATA PREPARATION FOR MCE}

As mentioned in the introduction, when viewed from the viability aspects of water heating options, the data required for performing $\mathrm{MCE}$ is essentially the perceptions of the stakeholders on the performance of the water heating options with respect to the multicriteria covering various dimensions of viability. Acquiring the necessary data requires the sub-phases viz. identifying the potential area of study, identifying the criteria and options for study, acquiring the data and finally preparation of the data to evolve the evaluation matrix for performing the MCE.

\subsection{Bangalore: The Study Area}

As a maiden attempt to evaluate the viability of DSHWS, the urban area Bangalore (fifth largest metropolitan area in India and capital city of Karnataka with geographic, demographic details as: $12^{\circ} 58^{\prime} \mathrm{N}$ latitude, $77^{\circ} 35^{\prime} \mathrm{E}$ longitude, $921 \mathrm{~m}$ altitude, area exceeding 2200 square kilometers) was taken as the study area in view of the prevailing conducive conditions for DSHWS such as consistent year round demand for hot water in the Bangalore households, due to lesser mean daily maximum/minimum temperatures and flatter variations in temperatures throughout the year (Figures 1; 2); favorable solar energy related conditions (See Figure 3); established

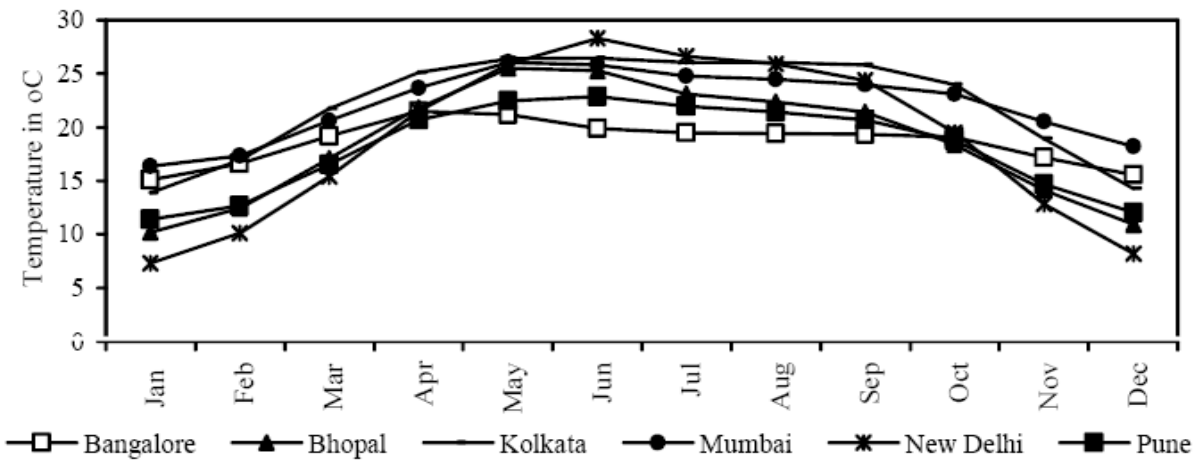

Figure 1: Mean daily minimum temperatures of selected urban cities [14].

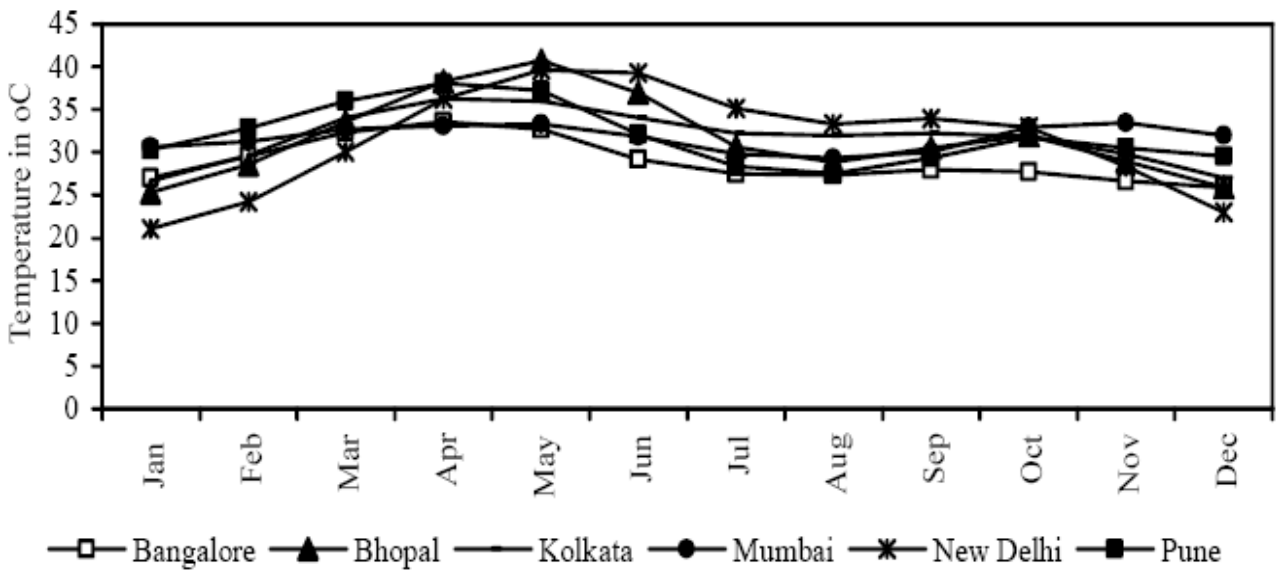

Figure 2: Mean daily maximum temperatures of selected urban cities [14]. 


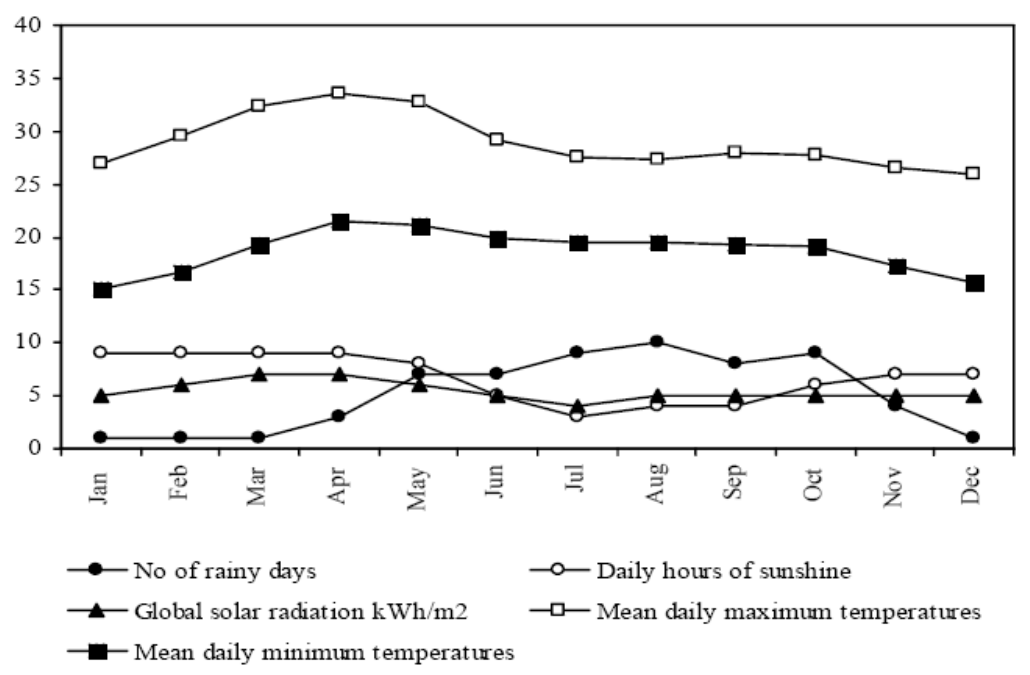

Figure 3: Variation of temperatures and solar parameters for Bangalore [15].

DSHWS manufacturing base with several large and small scale industries (nearly $60 \%$ of the manufacturers registered with MNRE are from Bangalore [16]).

\subsection{Definition of Criteria in Various Dimensions}

A broad list of 27 criteria was prepared based on earlier evaluations, various studies reported [2, 3, 4, 13] and perceptions of stakeholders. The identified criteria were grouped in to four dimensions of viability to form a hierarchy of criteria as shown in Figure 4. Eleven criteria (CA1-CA11) belonging to various technological issues of dimension is the heart of any water heating option selection. Five economic criteria (CA12-CA16) were identified for the present research work. The third dimension comprises six criteria (CA17CA22) related to the factors that contribute for the effective commercial dissemination. However good a water heating option may be with respect to all other dimensions, the option may not become viable until it satisfies the average users' social and behavioral requirements. The social and behavioral dimension comprises five criteria (CA23-CA27). Among the criteria considered, all except CA2, CA8, CA10, CA12, CA13, CA14, CA15, CA23, CA24 are maximization criteria.

\subsection{Definition of Options}

Various studies on domestic energy consumption patterns in India [17-20], indicate that electricity, LPG, kerosene are the dominating energy sources in urban India to meet the routine domestic energy needs including water heating. Accordingly, water heating options/devices viz. kerosene (KR), LPG (LG), electric immersion heater $(\mathrm{IH})$ and electric geyser $(\mathrm{EG})$ were considered as the competitors for DSHWS (SH). FPC based thermosyphon systems with electric back up are the DSHWS considered in this study.

\subsection{Data Collection and Development of Evaluation Matrix}

Stakeholders' perceptions and opinions on the performance of domestic water heating options with respect to identified criteria were obtained through individual consultation based survey. A questionnaire, with a rating section meant to seek information on (a) importance of each criterion in choosing any domestic water heating option and (b) performance of five domestic water heating options with respect to each criterion, was used as a survey instrument. The respondent was required to give the qualitative information by circling any one of the three choices viz. $\mathrm{H}$ (High), M (Medium), and L (Low). Three stakeholder groups viz. users; researchers involved in energy related works; professionals (manufacturers, consultants, officials of state and central promoting agencies) were identified and consulted. Average time taken for each interaction was around 20 minutes. Total valid responses were 2240 with the distribution as $73 \%$ users, $7.14 \%$ researchers, and $19.64 \%$ professionals.

The qualitative information given by each respondent was quantified by using three-point scales $(\mathrm{H}=6, \mathrm{M}=4, \mathrm{~L}=2$ for "importance of criteria" and "performance of options" w.r.t maximization criteria; reverse of above scale for "performance of options" w.r.t minimization criteria to convert the entire problem 


\begin{tabular}{|c|c|c|c|c|c|c|c|c|c|c|c|c|c|}
\hline Level 5 & KR & & & LG & & & IH & & & EC & & & SH \\
\hline Level 4 & $\begin{array}{c}\text { CA1 } \\
- \\
\text { CA4 }\end{array}$ & $\begin{array}{c}\text { CA5 } \\
- \\
\text { CA6 }\end{array}$ & CA7 & $\begin{array}{c}\text { CA8 } \\
- \\
\text { CA11 }\end{array}$ & $\begin{array}{c}\text { CA12 } \\
- \\
\text { CA13 }\end{array}$ & $\begin{array}{c}\text { CA14 } \\
- \\
\text { CA15 }\end{array}$ & CA16 & $\begin{array}{c}\text { CA17 } \\
- \\
\text { CA20 }\end{array}$ & $\begin{array}{c}\text { CA21 } \\
- \\
\text { CA22 }\end{array}$ & $\begin{array}{c}\text { CA23 } \\
- \\
\text { CA24 }\end{array}$ & CA25 & CA26 & CA27 \\
\hline Level 3 & $\mathrm{~T} 1$ & $\mathrm{~T} 2$ & T3 & $\mathrm{T} 4$ & $\mathrm{E} 1$ & E2 & E3 & C1 & $\mathrm{C} 2$ & $\mathrm{~S} 1$ & S2 & S3 & S4 \\
\hline Level 2 & \multicolumn{4}{|c|}{$\mathrm{T}$} & \multicolumn{3}{|c|}{$E$} & \multicolumn{2}{|c|}{ C } & \multicolumn{4}{|c|}{$\mathrm{S}$} \\
\hline Level 1 & \multicolumn{13}{|c|}{ Viability } \\
\hline
\end{tabular}

Notes:

KR: Kerosene option; LG: LPG option; IH: Immersion heater option; EG: Electric geyser option; SH: DSHWS option.

CA1: Compactness of the device, CA2: Fuel/Energy consumption rate, CA3: Usable life of the device, CA4: Device ranges, CA5: Overall quality of the device, CA6: Sophistication level of the device, CA7: Reliability of the device, CA8: Environmental pollution during actual use of the device, CA9: Ease of "installation and use" of the device, CA10: Operation and maintenance of the device, CA11: Use of the device for other purposes, CA12: Initial cost of the device, CA13: Interest rates on borrowed finances, CA14: Energy costs, CA15: Operation and maintenance costs, CA16: Subsidies to consumers, CA17: Warranties on the device, CA18: Brand status of the device, CA19: Supply channels, CA20: After sales service, CA21: Influence of environmental regulations in choosing the option, CA22: Influence of awareness policies in choosing the option, CA23: Restrictions from "house owner ship" to go for the option, CA24: Restrictions from "house type" to go for the option, CA25: Aesthetics and appealing value, CA26: Safety level of the option, CA27: Individual motivation to go for the option.

T1: Device design and performance criteria, T2: Device quality and sophistication criteria, T3: Site dependent criteria, T4: Usage criteria, E1: Initial costs related criteria, E2: Running costs related criteria, E3: Subsidies to consumers, C1: Market criteria, C2: Policy criteria, S1: Residence dependent criteria, S2: Aesthetics and appealing value, S3: Safety level of the option, S4: Individual motivation to go for the option.

T: Technical dimension; E: Economic dimension, C: Commercial dissemination dimension, S: Social and behavioural dimension.

Figure 4: Hierarchy of criteria for viability evaluation.

in to a maximization problem). Mean importance score of criteria and mean performance scores of each option with respect to each criterion are calculated as per the equations 1 and 2 .

$\delta_{j}=\frac{\sum \beta_{j}}{N}$

$\Omega_{i j}=\frac{\sum \gamma_{i j}}{N}$

where $\delta_{j}$ is the mean importance score of $j^{\text {th }}$ criterion, $\beta_{j}$ are the scores obtained from the perceptions of individual respondents for $j^{\text {th }}$ criterion, $\mathrm{N}$ is the total number of respondents, $\Omega_{i j}$ is the mean performance score of $i^{\text {th }}$ option on $j^{\text {th }}$ criterion, $\gamma_{i j}$ are the scores obtained from the perceptions of individual respondents for $i^{\text {th }}$ option on $j^{\text {th }}$ Criterion, $\mathrm{N}$ is the total number of respondents. Further, importance weightage of the individual criterion; mean importance scores for all the four dimensions of viability are calculated as per the equations 3 and 4 respectively.

$w_{j}=\frac{\delta_{j}}{\varepsilon_{j}}$

$\psi=\frac{\sum_{j=1}^{n} \delta_{j}}{n}$

where $w_{j}$ is the importance weightage of $j^{\text {th }}$ criterion and $\varepsilon_{j}$ is maximum favorable score for $j^{\text {th }}$ Criterion, $\psi$ represents mean importance score of a dimension and $n$ represents total number of criteria in that dimension. Additionally, mean weightages of the four dimensions of the viability were also calculated. Mean importance scores and weightage of the criteria are as presented in Table 1.

Table 1: Mean Importance Scores and Weightages of Criteria

\begin{tabular}{|c|c|c|}
\hline Criteria & Mean importance score & Weightage \\
\hline \hline CA1 & 4.77 & 0.79 \\
\hline CA2 & 5.85 & 0.97 \\
\hline CA3 & 5.69 & 0.95 \\
\hline CA4 & 4.92 & 0.82 \\
\hline CA5 & 5.85 & 0.97 \\
\hline CA6 & 5.08 & 0.85 \\
\hline CA7 & 6.00 & 1.00 \\
\hline CA8 & 5.54 & 0.92 \\
\hline CA9 & 5.54 & 0.92 \\
\hline CA10 & 5.69 & 0.95 \\
\hline CA11 & 4.62 & 0.77 \\
\hline CA12 & 5.69 & 0.95 \\
\hline CA13 & 4.50 & 0.75 \\
\hline CA14 & 5.54 & 0.92 \\
\hline CA15 & 5.23 & 0.87 \\
\hline CA16 & 3.69 & 0.62 \\
\hline CA17 & 5.38 & 0.90 \\
\hline CA18 & 5.54 & 0.92 \\
\hline CA19 & 5.54 & 0.92 \\
\hline CA20 & 6.00 & 1.00 \\
\hline CA21 & 5.69 & 0.95 \\
\hline CA22 & 6.00 & 1.00 \\
\hline CA23 & 5.23 & 0.87 \\
\hline CA24 & 5.17 & 0.86 \\
\hline CA25 & 5.54 & 0.92 \\
\hline CA26 & 5.85 & 0.97 \\
\hline CA27 & 5.83 & 0.97 \\
\hline & & \\
\hline
\end{tabular}


Critical analysis of mean importance scores and weightages of the criteria indicate the following interesting findings. All the dimensions assume a mean weightage greater than 0.8 . While mean weightages for three dimensions viz. technical dimension (0.90) commercial dissemination dimension (0.94) social and behavioural dimension (0.92) are more or less equal, mean weightage for economic dimension had been the lowest with a value of 0.82 . However, differences between the mean weightages of four dimensions of viability are marginal which supports the argument that viability of water heating options are greatly governed by these four dimensions.

With respect to individual criteria, respondents did not consider any criteria to be trivial as indicated by the weightage patterns of the individual criteria. Maximum weightage of the criteria was 1 and minimum criteria weightage was 0.62 . Nearly $2 / 3^{\text {rd }}$ of the criteria assumed weightages greater than or equal to 0.9 . Criteria such as CA2 (fuel/energy consumption rate), CA5 (overall quality of the device), CA7 (reliability of the device), CA12 (initial cost of the device) etc. are a part of this high weightage group. A total number of 8 criteria assumed weightages in between 0.75 and 0.9 . CA13 (interest rates on borrowed finances) had second least weightage with a value of 0.75 and $C A 16$ (subsidies to consumers) assumed a least weightage of 0.62. This implies that, interest rates on borrowed finances and subsidies to consumers play relatively less important role in choosing any water heating option, which may be a reflection of the improved economic status of the Bangalore users. However, their importance cannot be completely neglected when

Table 2: Evaluation Matrix Developed from the Survey Data

\begin{tabular}{|c|c|c|c|c|c|}
\hline Criteria & \multicolumn{5}{|c|}{ Water heating options } \\
\hline CA1 & 5.13 & 5.38 & 5.88 & 5.25 & 2.38 \\
\hline CA2 & 3.50 & 4.00 & 2.50 & 2.38 & 5.50 \\
\hline CA3 & 2.63 & 4.80 & 3.38 & 5.00 & 5.75 \\
\hline CA4 & 2.75 & 3.73 & 4.13 & 4.88 & 4.63 \\
\hline CA6 & 2.13 & 3.47 & 2.50 & 5.25 & 3.88 \\
\hline CA7 & 3.38 & 4.53 & 4.13 & 4.63 & 4.50 \\
\hline CA8 & 2.25 & 4.40 & 5.47 & 5.50 & 5.25 \\
\hline CA9 & 3.75 & 3.60 & 4.25 & 5.00 & 4.63 \\
\hline CA13 & 6.00 & 5.87 & 6.00 & 5.87 & 3.00 \\
\hline CA14 & 4.38 & 4.63 & 2.88 & 2.88 & 5.75 \\
\hline CA15 & 4.63 & 5.00 & 4.75 & 4.88 & 5.63 \\
\hline CA16 & 5.25 & 5.13 & 5.00 & 5.25 & 2.63 \\
\hline CA17 & 2.25 & 3.63 & 2.63 & 4.00 & 5.75 \\
\hline CA18 & 2.13 & 3.63 & 3.63 & 5.38 & 4.25 \\
\hline CA19 & 5.38 & 5.38 & 5.75 & 6.00 & 3.13 \\
\hline CA20 & 2.13 & 3.38 & 2.75 & 4.50 & 4.13 \\
\hline CA21 & 2.00 & 2.50 & 2.25 & 2.38 & 3.25 \\
\hline CA27 & 2.13 & 3.87 & 3.07 & 4.40 & 4.13 \\
\hline
\end{tabular}


looked from the view point of indirect subsidies promoting the use of certain water heating options.

Data on mean scores calculated as above which is needed for the MCE is summarized in evaluation matrix as represented in Table 2. Detailed discussions based on the data presented in the evaluation matrix are presented in the results and discussions section.

\section{SELECTION OF AGGREGATION METHODS}

Aggregation means, to summarize the performances of the options over the criteria to achieve the set objectives of MCE. Due to the fact that every MCE problem has its own characteristics and hence would theoretically require its own decision-aid method, several aggregation methods were evolved over the decades. The methods include weighted sum, preference ranking organization method for enrichment evaluation (PROMETHEE), multi attribute utility theory, analytical hierarchical process (AHP), different ELECTRE methods, multi objective programming, fuzzy logic based methods etc. Great number of methods available also presents a weakness, as it is not clear which method should be used for which situation. Choosing one method out of all the existing ones is itself a multi-criteria task.

In their review paper covering 90 published papers on multi-criteria decision making to sustainable energy planning, the Pohekar and Ramachandran [21] observed that AHP is the most popular technique followed by out ranking techniques including PROMETHEE. The main reason for the wide applicability of these methods in energy planning area could be due to the inherent advantages such as these methods are plausible, understandable and easily usable. In addition, qualitative criteria can also be addressed in these two methods.

Since Brans et al. [22] presented the PROMETHEE methods, these methods are being used extensively in a wide area of applications including energy planning area. Georgopoulou et al. [23] work on development of decision support system for group decision making for renewable energy exploitation, Topcu and Ulengin [24] work to evaluate the electricity generation alternatives of Turkey, Madlenerand Stagl [25] work to propose a methodology for the design of renewable energy policy are among the several reported works on the use of PROMETHEE for energy planning related activities.

Introduced by Saaty [26], AHP is another MCE method which has been used in a wide variety of application areas including energy planning area. Pohekar and Ramachandran [27] work to rank the cooking alternatives and to identify the potential areas for the improvement of parabolic solar cookers, Vashishta and Ramachandran [28] work to evaluate eight demand side management (DSM) strategies from a multi objective perspective, Nagesha and Balachandra [29] work to identify and rank the barriers for energy efficiency in the small scale industries etc., are among the innumerable number of works that utilized AHP in the energy planning area.

Owing to all of the above, in the present work, these two established and time tested aggregation methods viz. PROMETHEE and AHP were used to perform the MCE to study the viability of various water heating options.

\section{MCE BY PROMETHEE}

As per the established PROMETHEE based MCE procedure, computations for viability evaluation of water heating options involve (a) computation of preference functions (b) computation ofoutgoing flows, ingoing flows and net flow (multi-criteria preference index, MCPI) for all the water heating options.

\subsection{Computation of Preference Functions}

The preference functions $P(a, b)$, give the intensity of preference of water heating option "a" over water heating option " $b$ " as a function of the deviance of evaluation, $d(d=f(a)-f(b))$, where $f(a)$ and $f(b)$ are functions dependent on performance of water heating options "a" and "b". This preference function has the range of values between 0 and 1 such that
$P(a, b)=0$ if $d \leq 0$
no preference
$P(a, b)=0$ if $d>0$
weak preference.
$P(a, b)=1$ if $d>>0$
strong preference.
$P(a, b)=1$ if $d>>>0$
strict preference.

Since preference function $P(a, b)$ is a function of deviance of evaluation $d$, a generalized criterion has to be built for each criterion to calculate the preference function. Six different forms such as usual criterion, quasi criterion, Gaussian criterion etc., are proposed for PROMETHEE by Brans et al. [22]. For the present viability evaluation problem, usual criterion function was chosen in which even small difference makes the option preferred over the other. For this type of generalized criterion, there is indifference between 
water heating option " $a$ " and " $b$ " if and only of $f(a)=$ $f(b)$.

\subsection{Computation of multi-Criteria Preference Indices}

Having defined the deviance of evaluation $d$ and the preference function $P$ for each pair of options and for each criterion, a preference index $\pi(a, b)$, which expresses how and with which intensity water heating option "a" dominates water heating option " $b$ " over all the criteria, has to be defined.

Given the sets of preference functions, $P_{j}(a, b)$ and weights associated with each criterion, $w_{j}$ where $j$ is the criteria 1 to $\mathrm{m}, \pi(a, b)$ is defined as

$\pi(a, b)=\frac{\sum w \cdot P_{j}(a, b)}{\sum w_{j}}$

This $\pi(a, b)$ has its values ranging from 0 to 1 such that $\pi(a, b)=0$ implies a weak global preference of water heating option " $a$ " over water heating option " $b$ " and $\pi(a, b)=1$ implies a strong global preference. Similar computational logic and characteristics apply for $\pi(b, a)$ which expresses how water heating option " $b$ " dominates water heating option " $a$ ". From these computed values of $\pi(a, b)$ and $\pi(b, a)$ for each pair of options, two complete pre-orders viz. outgoing flow $\phi^{+}(a)$, and ingoing flow $\phi^{-}$can be constructed such that

$\phi^{+}(a)=\sum \pi(a, b)$

$\phi^{-}(a)=\sum \pi(b, a)$

In PROMETHEE complete pre-order is obtained, as the options are raked following decreasing order of $\phi$ (a) (MCPI), such that

$\phi(a)=\phi^{+}(a)-\phi^{-}(a)$

Using a software interface developed for the purpose, preference functions; MCPI for all the options were calculated and hence position of DSHWS in relation to the other water heating options was obtained. Results of these analyses and associated discussions are as presented in results and discussions section.

\section{MCE BY AHP}

The three steps in the evaluations by AHP viz. constructing hierarchies; comparative judgment; and synthesis of priorities which were applied for the present problem as described in the following sections. The first step of constructing hierarchy allows the complex decision to be structured into a hierarchy descending from an overall objective to various 'criteria', 'sub-criteria', and so on. Figure 4 shows the structural hierarchy, containing five levels, constructed for the present water heating systems' viability evaluation problem.

\subsection{Establishment of Comparative Judgments}

Once the hierarchy has been structured, the next step is to determine the priorities of elements at each level ('element'here means every member of the hierarchy). A set of pair wise comparison matrices of all elements in a level of the hierarchy with respect to an element of the immediately higher level are to be constructed so as to prioritize and convert individual comparative judgments into ratio scale measurements. These pair wise comparison matrices were obtained for the present viability evaluation problem using (a) a nine-point scale suggested by Saaty [26] which tells how much element $A$ is more important than element $B$ (b) Performances of 5 options with respect to 27 criteria as given by stakeholders. On the whole, 27 matrices at level 5; 8 matrices at level 4; 4 matrices at level 3; 1 matrix at level 2 have been generated. One of such matrices formed for pair wise comparisons at level 5 with respect to an element CA9 at level 4 is as shown Table 3.

Table 3: Pair Wise Comparison Matrix for Options with Respect to Criteria CA9

\begin{tabular}{|c|c|c|c|c|c|}
\hline & KR & LG & IH & EG & SH \\
\hline \hline KR & 1 & 1 & 0.500 & 0.250 & 0.333 \\
\hline LG & 1 & 1 & 0.333 & 0.250 & 0.333 \\
\hline IH & 2 & 3 & 1 & 0.333 & 0.500 \\
\hline EG & 4 & 4 & 3 & 1 & 2 \\
\hline SH & 3 & 3 & 2 & 0.500 & 1 \\
\hline
\end{tabular}

\subsection{Synthesis of Priorities and Measurement of Consistency}

After all pair wise comparison matrices are developed, the next step is to extract the relative importance implied by these comparisons. Saaty [26] asserts that, in order to obtain these relative importances, one has to estimate the right principal eigen vector of the comparison matrices. For a given pair wise comparison matrix, the corresponding 
maximum left eigen vector is approximated by using the geometric mean of each of a row. Corresponding priority vector is then obtained by dividing the numbers in the eigen vector with their sum. In AHP, the comparisons in a pair wise comparison matrix are considered to be adequately consistent if the corresponding consistency ratio is less than 10\% [26]. Standard AHP procedure as suggested by Saaty [26] was followed to compute the following using a software interface developed for the purpose.

- eigen vectors, maximum eigen value, consistency index, consistency ratios for each pair wise comparison matrix.

- $\quad$ Overall weight, W, for each option obtained by linear combination of products of criteria weights at various levels as per equation 9.

In this equation, " $w$ " represents the weight coefficients. The first number in the suffix of " $w$ " represents the number of level in the hierarchy and second number in suffix represents element number in that level. It may be noted that " $w_{5 k i}$ " represents the priorities of options with respect to elements in level 4, where " $k$ " represents the number of option. These overall weight coefficients for each of the option can be viewed as the index for viability for that particular option. Results and associated detailed discussions are as presented in results and discussions section.

Weigtage of water Heating Option =

$$
\begin{aligned}
& w_{21}\left[\begin{array}{l}
\left.w_{31}\left(\sum_{i=1}^{4} w_{4 i} w_{5 k i}\right)+w_{32}\left(\sum_{i=5}^{6} w_{4 i} w_{5 k i}\right)+\right] \\
w_{33}\left(w_{47} \times w_{5 k 7}\right)+w_{34}\left(\sum_{i=8}^{11} w_{4 i} w_{5 k i}\right)
\end{array}\right] \\
& +w_{22}\left[\begin{array}{l}
\left.w_{35}\left(\sum_{i=12}^{13} w_{4 i} w_{5 k i}\right)+w_{36}\left(\sum_{i=14}^{15} w_{4 i} w_{5 k i}\right)\right] \\
+w_{37}\left(w_{416} \times w_{5 k 16}\right)
\end{array}\right] \\
& +w_{23}\left[\begin{array}{l}
w_{38}\left(\sum_{i=17}^{20} w_{4 i} w_{5 k i}\right)+w_{39}\left(\sum_{i=21}^{22} w_{4 i} w_{5 k i}\right)
\end{array}\right] \\
& +w_{24}\left[\begin{array}{l}
w_{310}\left(\sum_{i=23}^{24} w_{4 i} w_{5 k i}\right)+w_{311}\left(w_{425} \times w_{5 k 25}\right) \\
+w_{312}\left(w_{426} \times w_{5 k 26}\right) \\
+w_{313}\left(w_{427} \times w_{5 k 27}\right)
\end{array}\right]
\end{aligned}
$$

\subsection{Observations from Evaluation Matrix}

Preliminary and peripheral analysis of the evaluation matrix (Table 2) indicate that DSHWS has got more strengths with respect to the criteria viz. fuel/energy consumption rate; usable life of the device; operation and maintenance of the device; energy costs; operation and maintenance costs; warranties on the device; influence of environmental regulations in choosing the option; influence of awareness policies/programs in choosing the option; safety level of the device. DSHWS exhibited weakness with respect to compactness of the device; device ranges; overall quality of the device, sophistication levels of the device, reliability of the device, ease of "installation and use" of the device; use of device for other purposes; initial cost of the device; interest rates on borrowed finances; subsidies to consumers; brand status; supply channels; after sales service; restrictions from "house ownership" to go for the option; restrictions from "house type" to go for the option; aesthetics and appealing value; individual motivation to for the option.

Most of the mean performance values for the electric geysers are either "high" or "medium". Similar to that of DSHWS, few criteria are having the low mean performance value. Mean performance values of immersion heaters on all criteria indicate that, there is, more or less, equal distribution of strengths and weaknesses. Kerosene option has got its strengths with respect to criteria such as compactness, ease of installation and use, lower operation and maintenance, lower initial cost, lower restrictions from house owners and house type, ready availability in the market etc. With respect to remaining criteria, kerosene option has shown a lower performance levels. Main strength of LPG is its usefulness of the device other purposes as indicated by its high mean performance value. Other strengths of LPG based on the mean performances are, no restrictions from house type or house ownership, compactness of the devices, well defined supply channel net work, low operation and maintenance etc. Poor after sales service, low sophistication levels etc. are among the significant weaknesses of LPG option.

\subsection{Salient Outcomes from PROMETHEE Analysis}

Using the evaluation matrix developed and following the evaluation procedure as explained earlier, preference functions for the options with respect to 
Table 4: Preference Functions for the Options with Respect to Compactness of the Device

\begin{tabular}{|c|c|c|c|c|c|c|c|c|c|c|}
\hline & \multicolumn{2}{|c|}{ KR } & \multicolumn{2}{|c|}{ LG } & \multicolumn{2}{|c|}{ IH } & \multicolumn{2}{|c|}{ EG } & \multicolumn{2}{|c|}{ SH } \\
\hline & $P(a, b)$ & $P(b, a)$ & $P(a, b)$ & $P(b, a)$ & $P(a, b)$ & $P(b, a)$ & $P(a, b)$ & $P(b, a)$ & $P(a, b)$ & $P(b, a)$ \\
\hline $\mathrm{KR}$ & 0 & 0 & 0 & 1 & 0 & 1 & 0 & 1 & 1 & 0 \\
\hline LG & 1 & 0 & 0 & 0 & 0 & 1 & 1 & 0 & 1 & 0 \\
\hline $\mathrm{IH}$ & 1 & 0 & 1 & 0 & 0 & 0 & 1 & 0 & 1 & 0 \\
\hline$E G$ & 1 & 0 & 0 & 1 & 0 & 1 & 0 & 0 & 1 & 0 \\
\hline $\mathrm{SH}$ & 0 & 1 & 0 & 1 & 0 & 1 & 0 & 1 & 0 & 0 \\
\hline
\end{tabular}

each criterion were obtained. Preference functions for one criterion viz. compactness of the device CA1 is as shown in Table 4. Table 5A and Table 5B represent the computed values of out going flows and ingoing flows respectively.

Table 6 represents the MCPI values of five water heating options. Option with the highest net $\phi$ (a) is considered to be the option with highest viability where as lower values of $\phi$ (a) indicate the lower viabilities. As it can be observed from the Table 6 , electric geyser option, with MCPI value of 1.6409 , is found to be the best viable option and kerosene option, with MCPI value of -1.9961 , is found to be the option with lowest viability. Water heating using DSHWS option is found to be the second best viable water heating option, with MCPI value of 0.9787 . The higher positive net MCPI for electric geyser and DSHWS options indicate that these two options have more strengths as compared to the weaknesses with respect to the criteria considered. Kerosene and electric immersion heater options have got more weaknesses compared to their strengths as indicated by the negative values of $\mathrm{MCPI}$, indicating that both of these options have got relatively low viability. LPG option has got the positive value of MCPI which is less than electric geyser option and DSHWS option. From the above it is clear that, relatively, LPG and electric geyser are the close competitors for DSHWS, while the other two options are distant competitors.

Table 5A: Preference Index and Outgoing Flows for the Options

\begin{tabular}{|c|c|c|c|c|c|c|}
\hline \multirow{2}{*}{ Water heating options } & \multicolumn{7}{|c|}{$\pi(a, b)$} & \multicolumn{2}{|c|}{ Water heating options } \\
\cline { 2 - 7 } & \multicolumn{3}{|c|}{$\phi^{+}(a)$} \\
\cline { 2 - 7 } & KR & LG & IH & EG & 0.2686 & 1.0019 \\
\hline \hline KR & 0.0000 & 0.1710 & 0.3217 & 0.2406 & 0.3477 & 2.2873 \\
\hline LG & 0.8669 & 0.0000 & 0.6755 & 0.3972 & 0.2749 & 1.7173 \\
\hline IH & 0.7892 & 0.3624 & 0.0000 & 0.2907 & 0.6195 & 2.8205 \\
\hline EG & 0.7847 & 0.6690 & 0.7472 & 0.0000 & 0.0000 & 2.4893 \\
\hline
\end{tabular}

Table 5B: Preference Index and Ingoing Flows for the Options

\begin{tabular}{|c|c|c|c|c|c|c|}
\hline \multirow{2}{*}{ Water heating options } & \multicolumn{5}{|c|}{$\pi(b, a)$} & \multicolumn{2}{c|}{ Water heating options } \\
\cline { 2 - 7 } & \multicolumn{3}{|c|}{$\phi^{-}(a)$} \\
\cline { 2 - 7 } & KR & LG & IH & EG & 0.7314 & 2.9981 \\
\hline \hline KR & 0.0000 & 0.8290 & 0.6783 & 0.7594 & 0.6523 & 1.7127 \\
\hline LG & 0.1331 & 0.0000 & 0.3245 & 0.6028 & 0.7251 & 2.2827 \\
\hline IH & 0.2108 & 0.6376 & 0.0000 & 0.7093 & 0.3805 & 1.1795 \\
\hline EG & 0.2153 & 0.3310 & 0.2528 & 0.000 & 0.0000 \\
\hline
\end{tabular}




\subsection{Salient Outcomes from AHP Analysis}

Table 7 to 10 represents the weightages at different levels in each of the dimensions of the problem and Table 11 represents the overall weights of the options.

A close look at the magnitudes of the criteria weights at various levels gives more insight in to the relative importance of various dimensions/criteria that define the existing viability position of water heating options. Even though each of the dimensions play a vital role in the viability of water heating options, the commercial dissemination dimension, with its highest relative weight, emerged out as the highly significant dimension among the four dimensions considered. Next dimensions in the order of priority are social and behavioural dimension; technical dimension and economic dimension. This shows that, criteria such as supply channels networks; brand status of the devices, after sales services, awareness policies/programs; safety levels, ownership of the residence; type of the residence, aesthetics \& appealing values of the

Table 7A: Weightages of Criteria in Technical Dimension

\begin{tabular}{|c|c|c|c|c|c|c|}
\hline \multirow{3}{*}{ Water heating options } & \multicolumn{6}{|c|}{ Technical dimension (0.159) } \\
\hline & \multicolumn{4}{|c|}{$\mathrm{T} 1(0.065)$} & \multicolumn{2}{|c|}{ T2 (0.142) } \\
\hline & CA1 (0.040) & $\begin{array}{c}\text { CA2 } \\
(0.532)\end{array}$ & $\begin{array}{c}\text { CA3 } \\
(0.354)\end{array}$ & $\begin{array}{c}\text { CA4 } \\
(0.074)\end{array}$ & $\begin{array}{c}\text { CA5 } \\
(0.900)\end{array}$ & $\begin{array}{c}\text { CA6 } \\
(0.100)\end{array}$ \\
\hline $\mathrm{KR}$ & 0.208 & 0.127 & 0.034 & 0.048 & 0.033 & 0.042 \\
\hline LG & 0.282 & 0.201 & 0.207 & 0.102 & 0.169 & 0.139 \\
\hline $\mathrm{IH}$ & 0.232 & 0.049 & 0.063 & 0.164 & 0.102 & 0.063 \\
\hline EG & 0.245 & 0.046 & 0.223 & 0.419 & 0.367 & 0.544 \\
\hline $\mathrm{SH}$ & 0.033 & 0.577 & 0.473 & 0.267 & 0.329 & 0.212 \\
\hline
\end{tabular}

Table 7B: Weightages of Criteria in Technical Dimension

\begin{tabular}{|c|c|c|c|c|c|}
\hline \multirow{3}{*}{ Water heating options } & \multicolumn{5}{|c|}{ Technical dimension (0.159) } \\
\cline { 2 - 6 } & \multicolumn{5}{|c|}{ T4 (0.072) } \\
\cline { 2 - 6 } & $\begin{array}{c}\text { CA7 }(\mathbf{0 . 7 2 1}) \\
\mathbf{( 1 . 0 0 0 )}\end{array}$ & $\begin{array}{c}\text { CA8 } \\
\mathbf{( 0 . 2 5 8 )}\end{array}$ & $\begin{array}{c}\text { CA9 } \\
\mathbf{( 0 . 2 5 8 )}\end{array}$ & $\begin{array}{c}\text { CA10 } \\
\mathbf{( 0 . 4 4 7 )}\end{array}$ & $\begin{array}{c}\text { CA11 } \\
\mathbf{( 0 . 0 3 7 )}\end{array}$ \\
\hline \hline KR & 0.061 & 0.027 & 0.087 & 0.083 & 0.286 \\
\hline LG & 0.265 & 0.094 & 0.081 & 0.213 & 0.563 \\
\hline IH & 0.144 & 0.337 & 0.165 & 0.213 & 0.042 \\
\hline EG & 0.265 & 0.337 & 0.411 & 0.098 & 0.043 \\
\hline SH & 0.265 & 0.205 & 0.256 & 0.393 & 0.066 \\
\hline
\end{tabular}

Table 8: Weightages of Criteria in Economic Dimension

\begin{tabular}{|c|c|c|c|c|c|}
\hline \multirow{2}{*}{$\begin{array}{c}\text { Water heating } \\
\text { options }\end{array}$} & \multicolumn{2}{|c|}{ E1 (0.357) } & \multicolumn{2}{|c|}{ E2 (0.589) } & \multicolumn{2}{c|}{$\begin{array}{c}\text { EA15 (0.054) } \\
\mathbf{( 0 . 1 0 0 )}\end{array}$} \\
\cline { 2 - 6 } & $\begin{array}{c}\text { CA12 } \\
\mathbf{( 0 . 9 0 0 )}\end{array}$ & $\begin{array}{c}\text { CA13 } \\
\mathbf{( 0 . 1 0 0 )}\end{array}$ & $\begin{array}{c}\text { CA14 } \\
\mathbf{( 0 . 9 0 0 )}\end{array}$ & 0.109 & 0.262 \\
\hline \hline KR & 0.379 & 0.242 & 0.165 & 0.205 & 0.228 \\
\hline LG & 0.131 & 0.242 & 0.218 & 0.125 & 0.199 \\
\hline IH & 0.379 & 0.242 & 0.046 & 0.165 & 0.397 \\
\hline EG & 0.085 & 0.242 & 0.046 & 0.048 \\
\hline
\end{tabular}


Table 9: Weightages of Criteria in Commercial Dissemination Dimension

\begin{tabular}{|c|c|c|c|c|c|c|}
\hline \multirow{3}{*}{ Water heating options } & \multicolumn{6}{|c|}{ Commercial dissemination dimension (0.551) } \\
\cline { 2 - 7 } & \multicolumn{3}{|c|}{ C1 (0.100) } & \multicolumn{3}{c|}{ C2 (0.900) } \\
\cline { 2 - 7 } & $\begin{array}{c}\text { CA17 } \\
\mathbf{( 0 . 0 5 1 )}\end{array}$ & $\begin{array}{c}\text { CA18 } \\
\mathbf{( 0 . 1 2 4 )}\end{array}$ & $\begin{array}{c}\text { CA19 } \\
\mathbf{( 0 . 1 2 4 )}\end{array}$ & $\begin{array}{c}\text { CA20 } \\
\mathbf{( 0 . 7 0 1 )}\end{array}$ & $\begin{array}{c}\text { CA21 } \\
(\mathbf{0 . 9 0 0 )}\end{array}$ & $\begin{array}{c}\text { CA22 } \\
(\mathbf{0 . 1 0 0 )}\end{array}$ \\
\hline \hline KR & 0.039 & 0.032 & 0.170 & 0.045 & 0.086 & 0.071 \\
\hline LG & 0.126 & 0.119 & 0.170 & 0.133 & 0.181 & 0.121 \\
\hline IH & 0.058 & 0.119 & 0.266 & 0.079 & 0.138 & 0.071 \\
\hline EG & 0.191 & 0.533 & 0.360 & 0.446 & 0.158 & 0.196 \\
\hline SH & 0.586 & 0.196 & 0.034 & 0.296 & 0.437 & 0.541 \\
\hline
\end{tabular}

Table 10: Weightages of Criteria in Social and Behavioural Dimension

\begin{tabular}{|c|c|c|c|c|c|}
\hline \multirow{3}{*}{ Water heating options } & \multicolumn{5}{|c|}{ Social and behavioural dimension $(0.251)$} \\
\hline & \multicolumn{2}{|c|}{$\mathrm{S} 1(0.037)$} & \multirow{2}{*}{$\begin{array}{c}\mathrm{S} 2(0.110) \\
\text { CA25 } \\
(1.000)\end{array}$} & \multirow{2}{*}{$\begin{array}{c}\mathrm{S} 3(0.427) \\
\text { CA26 } \\
(1.000)\end{array}$} & \multirow{2}{*}{$\begin{array}{c}\text { S4 }(0.427) \\
\text { CA27 } \\
(1.000)\end{array}$} \\
\hline & $\begin{array}{c}\text { CA23 } \\
(0.900)\end{array}$ & $\begin{array}{c}\text { CA24 } \\
(0.100)\end{array}$ & & & \\
\hline $\mathrm{KR}$ & 0.278 & 0.206 & 0.039 & 0.063 & 0.043 \\
\hline LG & 0.377 & 0.237 & 0.245 & 0.106 & 0.199 \\
\hline $\mathrm{IH}$ & 0.194 & 0.272 & 0.058 & 0.041 & 0.088 \\
\hline$E G$ & 0.117 & 0.237 & 0.496 & 0.190 & 0.381 \\
\hline $\mathrm{SH}$ & 0.033 & 0.047 & 0.162 & 0.601 & 0.289 \\
\hline
\end{tabular}

Table 11: Overall Relative Weights and Ranking Pattern for Options

\begin{tabular}{|c|c|c|c|c|c|}
\hline \multirow{2}{*}{} & \multicolumn{4}{|c|}{ Water heating options } \\
\cline { 2 - 6 } & KR & LG & IH & EG & SH \\
\hline \hline Overall relative weights & 0.079 & 0.183 & 0.117 & 0.227 & 0.395 \\
\hline Rank & 5 & 3 & 4 & 2 & 1 \\
\hline
\end{tabular}

devices, etc. assumed a key role in deciding the viability of any water heating option. Magnitudes of overall relative weights obtained for different water heating options indicate that DSHWS, electric geyser and LPG options have relatively higher strengths compared to the remaining two options. This implies that, relatively, LPG and electric geyser are the close competitors for DSHWS where as the other two options are distant competitors. This result is in accordance with the result obtained from PROMETHEE analysis.

\section{CONCLUSION}

This work is a maiden attempt to use MCE techniques to evaluate the viability of DSHWS vis-à-vis other competing water heating options. A large number of criteria covering the four dimensions of viability have been identified and used to evaluate the viability of DSHWS. The research work carried out identified the strengths and weaknesses of DSHWS in terms of various criteria that have a bearing on the viability of DSHWS. The results obtained from both PROMETHEE and AHP based viability studies of DSHWS demonstrate the use of these methods for quantifying the viability of a renewable energy system. The evaluations suggest that, in order to promote the wide spread use of DSHWS as alternative for its close competitors, policy/administrative/technological interventions may be made to improve on supply channel networks, brand status of the devices, after sales service, awareness policies/programs, aesthetics \& appealing values of the devices etc. The analytical framework used in the present work to evaluate the viability of DSHWS and hence to identify, weigh and prioritize the issues for improving the 
viability, can be used for any other geographic area to study the factors affecting the dissemination of DSHWS.

\section{REFERENCES}

[1] Ministry of new and renewable energy. Cumulative deployment of various Renewable Energy Systems/ Devices in the country as on 31/01/2012.Government of India, http://www.mnre.gov.in/mission-and-vision-2/achievements, 2012.

[2] Reddy BS. Barriers to the diffusion of renewable energy technologies - A case study of the state of Maharastra, India. Denmark: UNEP Collaborating Centre on Energy and Environment, Riso Natl Lab 2001.

[3] Reddy BS, Painuly JP. Diffusion of renewable energy technologies-barriers and stakeholders' perspectives. Renewable Energy 2004; 29(9): 1431-47. http://dx.doi.org/10.1016/j.renene.2003.12.003

[4] Dimitrios KS, Emmanuel GK. Solar systems diffusion in local markets. Energy Policy 2004; 32: 2007-18. http://dx.doi.org/10.1016/S0301-4215(03)00173-3

[5] Chandrasekhar B, Kandpal TC. Effect of financial and fiscal incentives on the effective capital cost of solar energy technologies to the user. Solar Energy 2005; 78: 147-56. http://dx.doi.org/10.1016/j.solener.2004.05.003

[6] Sunderasan S. Policy support for the evolving solar water heating industry. Refocus 2006; 7(2): 46-49.

[7] Chandrasekhar B, Kandpal TC. An opinion survey based assessment of renewable energy technology development in India. Renewable Sustainable Energy Rev 2007; 11: 688701.

http://dx.doi.org/10.1016/j.rser.2005.04.001

[8] Rao KU, Ravindranath $\mathrm{NH}$. Policies to overcome barriers to the spread of bio energy technologies in India. Energy Sustainable Dev 2002; 6(3): 59-73. http://dx.doi.org/10.1016/S0973-0826(08)60326-9

[9] Gupta CL. Role of renewable energy technologies in generating sustainable livelihoods. Renewable Sustainable Energy Rev 2003; 7(2): 155-74. http://dx.doi.org/10.1016/S1364-0321(03)00006-6

[10] Pohekar SD, Dinesh K, Ramachandran M. Dissemination of cooking energy alternatives in India - a review. Renewable Sustainable Energy Rev 2005; 9: 379-93. http://dx.doi.org/10.1016/j.rser.2004.05.001

[11] Pohekar SD, Ramachandran M. Hierarchical approach to evaluation and promotion of parabolic solar cookers in India. Energy Educ Sci Technol 2005; 14(2): 81-91.

[12] Malhotra $P$, Neudoerffer CR, Dutta S. A participatory process for designing cooking energy programmes with women. Biomass Bioenergy 2004; 26: 147-69. http://dx.doi.org/10.1016/S0961-9534(03)00083-7

[13] Painuly JP. Barriers to renewable energy penetration; a framework for analysis. Renewable Energy 2001; 24: 73-89. http://dx.doi.org/10.1016/S0960-1481(00)00186-5
[14] Indian Meteorological Department. Climate normals for important cities. Government of India, http://www.imd.ernet.in/section/climate/, 2006.

[15] Mani A, Rangarajan S. Solar radiation over India. New Delhi: Allied Publishers 1982.

[16] Ministry of New and Renewable Energy. FPC Manufactures Solar Water Heating System. Government of India. http://mnre.gov.in/information/manufacturesindustriesarchitec tsconsulting-organisation/. 2012

[17] Reddy BS. Overcoming the energy efficiency gap in India's household sector. Energy Policy 2003; 31: 1117-27. http://dx.doi.org/10.1016/S0301-4215(02)00220-3

[18] Brinda V, Kumar KSK. Cooking fuel use patterns in India: 1983-2000. Energy Policy 2005; 33: 1021-36. http//dx doi.org/10.1016/i.enpol.2003.11.002

[19] NSSO. Results of the National sample survey organisation for the household sector. New Delhi: National Sample Survey Organization 2001.

[20] ESMAP. Access of the poor to clean household fuels in India Report 263/03. Washington DC: Joint UNDP/World Bank Energy Sector Management Assistance Programme 2003.

[21] Pohekar SD, Ramachandran M. Application of multi - criteria decision making to sustainable energy planning - A review. Renewable Sustainable Energy Rev 2004; 8: 365-81. http://dx.doi.org/10.1016/.irser.2003.12.007

[22] Brans JP, Vincke PH, Mareschal B. How to select and how to rank projects: The PROMETHEE method. Eur J Operat Res 1986; 24 (2): 228-38. http://dx.doi.org/10.1016/0377-2217(86)90044-5

[23] Georgopoulou E, Sarafidis Y, Diakoulaki D. Design and implementation of a group DSS for sustaining renewable energies exploitation. Eur J Operat Res 1998; 109(2): 483500.

http://dx.doi.org/10.1016/S0377-2217(98)00072-1

[24] Topcu YI, Ulengin F. Energy for the future: An integrated decision aid for the case of Turkey. Energy 2004; 29: 137-54 http://dx.doi.org/10.1016/S0360-5442(03)00160-9

[25] Madlener R, Stagl S. Sustainability-guided promotion of renewable electricity generation. Ecol Econom 2005; 53(2): 147-67.

http://dx.doi.org/10.1016/j.ecolecon.2004.12.016

[26] Saaty TL. The analytical hierarchy process. New York: McGraw-Hill 1980.

[27] Pohekar SD, Ramachandran M. Hierarchical approach to evaluation and promotion of parabolic solar cookers in India. Energy Educ Sci Technol 2005; 14(2): 81-91.

[28] Vashishta S, Ramachandran M. Multi criteria evaluation of demand side management (DSM) implementation strategies in the Indian power sector. Energy 2006; 31(12): 2210-25. http://dx.doi.org/10.1016/j.energy.2005.10.005

[29] Nagesha N, Balachandra P. Barriers to energy efficiency in small industry clusters: Multi-criteria-based prioritization using the analytic hierarchy process. Energy 2006; 31(12): 1969-83.

http://dx.doi.org/10.1016/i.energy.2005.07.002 